\title{
Synergistic killing of human small cell lung cancer cells by the Bcl-2-inositol 1,4,5-trisphosphate receptor disruptor BIRD-2 and the BH3-mimetic ABT-263
}

\author{
EF Greenberg ${ }^{1,2,3}$, KS McColl $^{1,3}$, F Zhong ${ }^{1,3}$, G Wildey ${ }^{1,3}$, A Dowlati ${ }^{1,3}$ and CW Distelhorst ${ }^{\star, 1,3}$
}

Small cell lung cancer (SCLC) has an annual mortality approaching that of breast and prostate cancer. Although sensitive to initial chemotherapy, SCLC rapidly develops resistance, leading to less effective second-line therapies. SCLC cells often overexpress $\mathrm{Bcl}-2$, which protects cells from apoptosis both by sequestering pro-apoptotic family members and by modulating inositol 1,4,5trisphosphate receptor $\left(\mathrm{IP}_{3} \mathrm{R}\right)$-mediated calcium signaling. BH3-mimetic agents such as ABT-263 disrupt the former activity but have limited activity in SCLC patients. Here we report for the first time that Bcl-2-IP ${ }_{3}$ receptor disruptor-2 (BIRD-2), a decoy peptide that binds to the $\mathrm{BH} 4$ domain of $\mathrm{Bcl}-2$ and prevents $\mathrm{Bcl}-2$ interaction with $\mathrm{IP}_{3} \mathrm{Rs}$, induces cell death in a wide range of SCLC lines, including ABT-263-resistant lines. BIRD-2-induced death of SCLC cells appears to be a form of caspase-independent apoptosis mediated by calpain activation. By targeting different regions of the Bcl-2 protein and different mechanisms of action, BIRD-2 and $A B T-263$ induce cell death synergistically. Based on these findings, we propose that targeting the $B c \mid-2-I_{3} R$ interaction be pursued as a novel therapeutic strategy for SCLC, either by developing BIRD-2 itself as a therapeutic agent or by developing smallmolecule inhibitors that mimic BIRD-2.

Cell Death and Disease (2015) 6, e2034; doi:10.1038/cddis.2015.355; published online 31 December 2015

Lung cancer accounts for $12 \%$ of all new cancers worldwide and is a leading cause of cancer-related mortality in the United States. ${ }^{1-3}$ Although small cell lung cancer (SCLC) comprises only $15 \%$ of lung cancer cases, ${ }^{2,3}$ it has an annual mortality rate approaching that of breast and prostate cancer. ${ }^{4}$ Compared with the more common non-small cell lung cancer (NSCLC), SCLC is more aggressive and associated with rapid development of metastasis. ${ }^{2}$ Moreover, although SCLC is more responsive to chemotherapy and radiation therapy initially, it typically relapses quickly with treatment-resistant disease. ${ }^{2}$ In contrast to dramatic advances in chemotherapy and personalized medicine in other malignancies, the life expectancy of SCLC patients has remained $<2$ years for decades and is $<1$ year for patients with extensive disease. ${ }^{5,6}$ The lethality of SCLC is attributed in part to the development of resistance to standard combination chemotherapies, underscoring the need to develop novel therapeutic approaches based on understanding the molecular and cellular biology of SCLC. 5,6

Evasion from apoptosis is a major hallmark of cancer and a prominent factor underlying drug resistance in SCLC. ${ }^{3}$ Multiple mechanisms contribute to apoptosis resistance in SCLC, including elevated expression of the antiapoptotic Bcl-2 protein $^{3}$ (Supplementary Figure S1). Tsujimoto and colleagues discovered elevated levels of Bcl-2 mRNA and protein in SCLC cells not long after their identification of $\mathrm{Bcl}-2$ as the protein product of the $b c l-2$ gene in follicular lymphoma. ${ }^{7,8}$
Subsequently, immunohistochemistry of 164 primary SCLC samples revealed $76 \%$ were positive for $\mathrm{Bcl}-2$, a finding substantiated by microarray detection of increased BCL-2 mRNA levels in $84 \%$ of SCLC samples ${ }^{9,10}$ and by genomic sequencing of circulating SCLC tumor cells. ${ }^{11}$ Moreover, proteomic profiling documented that $\mathrm{Bcl}-2$ is more highly expressed in SCLC than in NSCLC, reflecting the vastly different biology of these lung cancer subtypes. ${ }^{12}$

The major known function of $\mathrm{Bcl}-2$ is to bind and sequester BH3-only proteins such as Bim, preventing these proteins from inducing apoptosis. ${ }^{13-15}$ Therefore, a major investment has been made in targeting this interaction for cancer treatment. The interaction takes place in a hydrophobic groove on $\mathrm{Bcl}-2$ and the therapeutic strategy for targeting this interaction has been to develop small molecules, BH3-mimetic agents, which bind in the hydrophobic groove and induce apoptosis by displacing the $\mathrm{BH} 3-o n l y$ proteins. This approach has been reviewed in detail. ${ }^{14,15,16}$

Among BH3-mimetic agents advancing through clinical trials for both hematological malignancies ${ }^{15,17}$ and solid tumors $^{18}$ are ABT-737 and its orally bioavailable derivative ABT-263 (Navitoclax). Reported studies of ABT-199, a selective inhibitor of $\mathrm{Bcl}-2$, are at present limited to hematological malignancies. ${ }^{18}$ In screening a large number of cancer cell lines, the pioneering work of Oltersdorf et al. ${ }^{19}$ demonstrated potent single-agent activity of ABT-737 against cell lines representative of lymphoid malignancies and SCLC.

\footnotetext{
${ }^{1}$ Division of Hematology/Oncology, Department of Medicine, Case Western Reserve University School of Medicine and University Hospitals Case Medical Center, Cleveland, OH, USA; ${ }^{2}$ Department of Medicine, MetroHealth Medical Center, Cleveland, OH, USA and ${ }^{3} \mathrm{Case}$ Comprehensive Cancer Center, Cleveland, OH, USA ${ }^{*}$ Corresponding author: CW Distelhorst, Division of Hematology/Oncology, Department of Medicine, Case Western Reserve University School of Medicine and University Hospitals Case Medical Center, 2103 Cornell Road, WRB3-301, Cleveland, OH 44106, USA. Tel: 216368 4546; Fax: 216 368 8919; E-mail: cwd@case.edu Abbreviations: BIRD-2, Bcl-2 IP3 receptor disruptor-2; Cl, Combination Index; CLL, chronic lymphocytic leukemia; CTG, CellTiter-Glo; ER, endoplasmic reticulum; IP $\mathrm{P}_{3}$, inositol 1,4,5-trisphosphate receptor; NSCLC, non-small cell lung cancer; RFP, red fluorescent protein; SCLC, small cell lung cancer; Scr, scrambled BIRD-2 Received 11.6.15; revised 02.11.15; accepted 03.11.15; Edited by M Diederich
} 
Clinical trials of ABT-263, an orally bioavailable version of $\mathrm{ABT}-737$, achieved overall response rates ranging from as high as $35 \%$ in relapsed/refractory chronic lymphocytic leukemia (CLL) and $22 \%$ in follicular lymphoma. ${ }^{17}$ Reported responses are generally less in solid tumors with the notable exception of SCLC. ${ }^{18}$ But even in SCLC, activity of ABT-263 is limited in comparison to hematological malignancies, with 1 of the 39 (3\%) of patients achieving a partial response to ABT-263 and 9 of the $37(23 \%)$ achieving stable disease in a phase I clinical trial. $^{20}$ This experience suggests a need to develop additional ways of targeting Bcl-2 for cancer treatment.

A potential alternative therapeutic target for $\mathrm{Bcl}-2$-positive malignancies involves interaction of $\mathrm{Bcl}-2$ with the inositol 1,4,5-trisphosphate receptor $\left(\mathrm{IP}_{3} \mathrm{R}\right)$, an $\mathrm{IP}_{3}$-gated $\mathrm{Ca}^{2+}$ channel located on the endoplasmic reticulum (ER). Bcl-2 is located not only on the outer mitochondrial membrane but also on the ER, and at both of these locations, it functions as a potent inhibitor of apoptosis. ${ }^{21-23}$ ER-localized Bcl-2 interacts with $\mathrm{IP}_{3} \mathrm{Rs}$ and inhibits apoptosis by preventing excessive $\mathrm{IP}_{3} \mathrm{R}$-mediated $\mathrm{Ca}^{2+}$ transfer from the ER lumen into the cytoplasm and nearby mitochondria. ${ }^{24-26}$ Notably, regions of $\mathrm{Bcl}-2$ involved in binding $\mathrm{BH} 3-$ only proteins and $\mathrm{IP}_{3} \mathrm{Rs}$ are entirely different. Whereas $\mathrm{BH}$-only proteins and their BH3-mimetic counterparts bind in a hydrophobic groove composed of $\mathrm{BH} 3$ domains $1-3$ of $\mathrm{Bcl}-2,{ }^{13,14}$ the $\mathrm{BH} 4$ domain of $\mathrm{Bcl}-2$ is necessary for interaction with $\mathrm{IP}_{3} \mathrm{Rs}^{27}$ To develop a peptide inhibitor of $\mathrm{Bcl}-2-\mathrm{IP}_{3} \mathrm{R}$ interaction, we identified the Bcl-2-binding region on the $\mathrm{IP}_{3} \mathrm{R}$ and developed a small synthetic 20 amino-acid peptide corresponding to this region. ${ }^{28}$ This peptide, when fused to the cell-penetrating peptide of HIV TAT, binds to the $\mathrm{BH} 4$ domain of $\mathrm{Bcl}-2$ and functions as a decoy peptide, inhibiting $\mathrm{Bcl}-2-\mathrm{IP}_{3} \mathrm{R}$ interaction. ${ }^{29,30}$ We currently refer to this peptide as BIRD-2 (Bcl-2-IP ${ }_{3}$ Receptor Disruptor2), having formerly named it TAT-IDP $P_{D D / A A} \cdot{ }^{31}$ By disrupting the $\mathrm{Bcl}-2-\mathrm{IP}_{3} \mathrm{R}$ interaction, BIRD-2 abrogates $\mathrm{Bcl}-2$ control over $\mathrm{IP}_{3} \mathrm{R}$-mediated $\mathrm{Ca}^{2+}$ elevation and induces $\mathrm{Ca}^{2+}$-mediated apoptosis in primary human CLL cells ${ }^{29}$ and diffuse large B-cell lymphoma cells. ${ }^{32}$ Notably, BIRD-2 does not kill normal cells, including human lymphocytes isolated from peripheral blood ${ }^{29}$ and normal murine embryonic fibroblasts (F Zhong and C Distelhorst, unpublished data).

The present investigation was undertaken to determine whether $\mathrm{Bcl}-2-\mathrm{IP}_{3} \mathrm{R}$ interaction is a potentially useful therapeutic target in SCLC. In support of this concept, we find the majority of SCLC lines tested are sensitive to BIRD-2-induced apoptosis and that BIRD-2 induces apoptosis in several ABT-263-resistant SCLC lines. BIRD-2, we find, lacks generalized cytotoxicity as it does not induce cell death in NSCLC lines or a normal lung epithelial line. On the other hand, we find that BIRD-2 and ABT-263 synergize in killing SCLC cells. These findings for the first time provide preclinical evidence of the potential value of targeting both antiapoptotic mechanisms of Bcl-2 for the treatment of SCLC.

\section{Results}

BIRD-2-induced cell death. To detect BIRD-2-induced cell death, 15 SCLC lines were treated with a range of concentrations of BIRD-2 in parallel with a scrambled version of BIRD-2 (Scr) to control for non-specific peptide-mediated toxicity. After $48 \mathrm{~h}$, cell viability was measured using the CellTiter-Glo (CTG) assay. Equivalent results were obtained using the AlamarBlue viability assay (data not shown). Based on these findings, IC50 values were determined (Figure 1a). BIRD-2 IC50 values were at least two-fold lower than Scr IC50 values in all SCLC lines except DMS454 and H1688, indicating that all but two of the SCLC lines are sensitive to BIRD-2-induced cell death. The sensitivity of individual lines varied considerably, as illustrated in Figures $1 \mathrm{~b}$ and c. Among the more sensitive lines, $\mathrm{H} 2171$ and $\mathrm{H} 1092$, decreased viability was detected within $8 \mathrm{~h}$ following BIRD-2 addition (Figures 1d and e). Also, BIRD-2 induced cell death only in SCLC cells, showing little activity against either NSCLC or normal lung epithelial cells (Figure 1f).

The same SCLC lines were also treated with ABT-263. IC50 values for ABT-263 and BIRD-2 are detailed in Supplementary Table S1 and summarized graphically in Figure 1g. The IC50 values reflect a range of sensitivities to BIRD-2 and ABT-263, without a correlation between IC50s for BIRD-2 and ABT-263 (correlation coefficient 0.11 ). ABT-263 resistance generally is defined as an IC50 $>1 \mu \mathrm{M}$, indicated by the horizontal line in Figure 1g. ${ }^{19,33}$ According to this definition, 6 of the 15 SCLC lines were sensitive to ABT-263. If we define BIRD-2 sensitivity as BIRD-2 IC50 values at least two-fold lower than Scr IC50 values, BIRD-2 induces cell death in six of the nine ABT-263-resistant SCLC cell lines (H2029, H378, DMS79, H446, H82, H526).

In summary, the preceding findings provide the first indication that targeting $\mathrm{Bcl}-2-\mathrm{IP}_{3} \mathrm{R}$ interaction, as we do with BIRD-2, can induce cell death in SCLC lines. Moreover, the findings suggest that, if therapeutic agents mimicking BIRD-2's action could be developed in the future, they might be of value in treating BH3-mimetic SCLC.

Given that BIRD-2 and BH3-mimetic agents target different mechanisms by which $\mathrm{Bcl}-2$ inhibits apoptosis, we tested whether combining these agents would synergistically induce cell death in SCLC cells. Consistent with this hypothesis, submaximal doses of BIRD-2 and ABT-263 significantly increased cell death in H2171 SCLC cells (Figure 1h). To establish synergy between BIRD-2 and ABT-263, cells were treated with a constant ABT-263 to BIRD-2 ratio over an entire dose-response range. This enabled mathematical assessment of synergistic versus additive cell killing using the CompuSyn software to calculate Combination Index (Cl) values. ${ }^{34}$ Using a $\mathrm{Cl}$ value of $<1$ as indicative of synergy, co-treatment of SCLC cells with BIRD-2 and ABT-263 consistently induced synergistic cytotoxicity in 5 of the 15 SCLC lines: H2171, H250, H1092, H526, and H1048. Three representative experiments are summarized in Figures $2 \mathrm{a}-\mathrm{c}$ where bar graphs document synergistic loss of viability. Synergy is also illustrated with the use of isobolograms (Figures $2 d-f$ ), in which points below the lines indicate synergistic cytotoxicity, points on the lines indicate additive cytotoxicity, and points above the lines indicate antagonism. Notably, synergy with BIRD-2 and ABT-263 was still present at high drug effect levels, emphasizing the potential therapeutic relevance of this combination. ${ }^{34}$

Overall, these findings indicate that BIRD-2 is cytotoxic to a large proportion of SCLC cells tested here. Moreover, the 
a

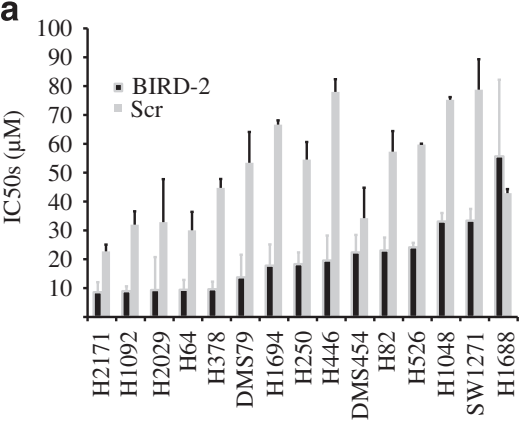

d

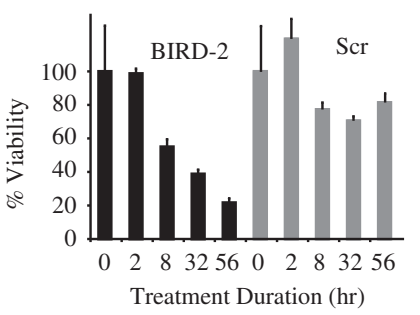

g

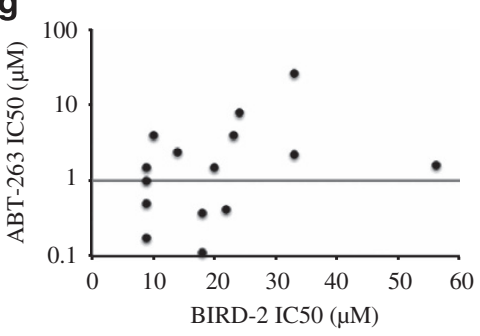

b

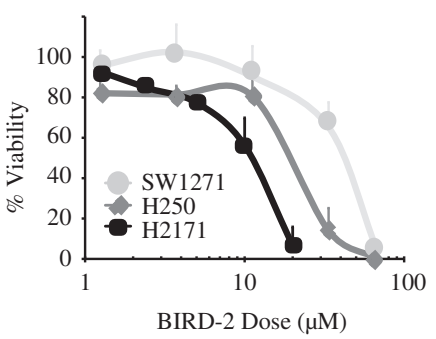

e

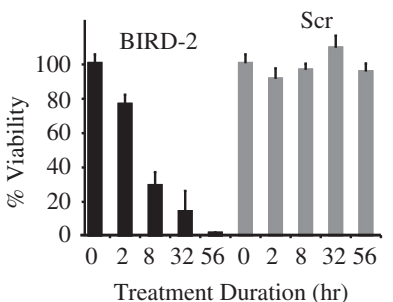

C
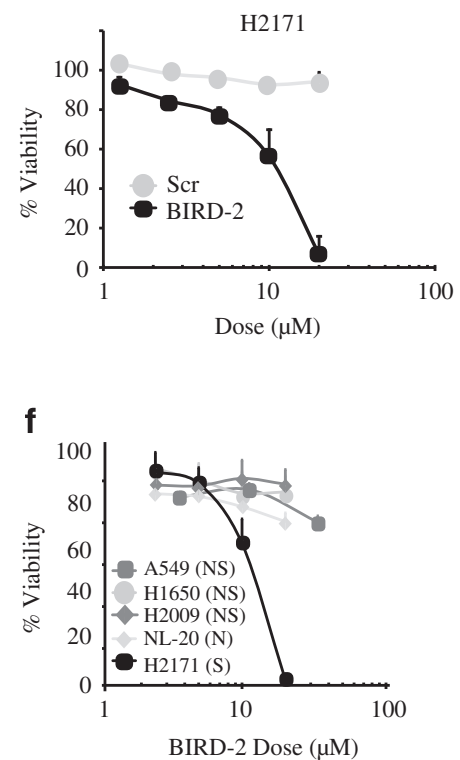



Figure 1 Cell death induction by BIRD-2. (a) IC50s of BIRD-2 and Scr control peptide (scrambled version of BIRD-2) in SCLC lines treated for $48 \mathrm{~h}$ with a broad range of peptide concentrations. Full dose-response curves were repeated at least three times. (b) Representative dose-response curves of SCLC lines treated for $48 \mathrm{~h}$ with BIRD-2. (c) Representative dose-response curves comparing H2171 cells treated for $48 \mathrm{~h}$ with BIRD-2 or Scr. (d and e) Time course of cell death induction by BIRD-2 in SCLC lines treated with $15 \mu \mathrm{M}$ (H2171) or $20 \mu \mathrm{M}$ (H1092) BIRD-2 or Scr at corresponding concentrations. (f) Dose-response curves comparing BIRD-2 sensitivity in SCLC cells (S), NSCLC cells (NS), and normal lung epithelial cells (N), each treated for $24 \mathrm{~h}$ with BIRD-2 at the indicated concentrations. (g) Graph based on data in Supplementary Table S1 comparing IC50s for BIRD-2 and ABT-263; each symbol represents an individual SCLC line. The horizontal line corresponds to an ABT-263 IC50 of $1 \mu \mathrm{M}$. (h) H2171 cells were treated for $48 \mathrm{~h}$ with variable concentrations of BIRD-2, ABT-263, or 127 : 1 BIRD-2+ABT-263 (BIRD-2 IC50 to ABT-263 IC50 ratio of 127 : 1). Cell viability was measured by CTG assay

findings indicate synergistic activity of BIRD-2 in combination with ABT-263. Finally, BIRD-2-induced cell death appears selective for SCLC, as NSCLC lines are much less sensitive to BIRD-2-induced cell death. The latter observation is consistent with expression data indicating that SCLC has higher levels of Bcl-2 than NSCLC (Supplementary Figure S1).

$\mathrm{Ca}^{2+}$-mediated apoptosis in BIRD-2-treated SCLC. To investigate the role of apoptosis in BIRD-2-induced cell death, we assessed several markers of apoptosis. An increase of Annexin V positivity, a marker of very early changes associated with apoptosis, was detected within $2 \mathrm{~h}$ of adding BIRD-2 to H2171 SCLC cells, compared with untreated and control Scr peptide-treated cells (Figures $3 a$ and b). Note that non-viable propidium iodide-positive cells were detected in untreated and Scr-treated cells (Figures 3a and $b$ ). This is likely due to the requirement of vigorous pipetting to disrupt large clumps of SCLC cells found in culture. Because of the tendency of SCLC cells to form clumps, we turned to the use of IncuCyte ZOOM live cell imaging fluorescence microscopy. This technique analyzes cell viability and other cellular characteristics in a controlled environment tissue culture chamber without a need to disrupt cellular clumps. Red fluorescent protein (RFP)-expressing SCLC cells were used in this method to quantify caspase $3 / 7$ activity (Figure $3 c$ ) and nuclear condensation (Figure 3d) at 2-h intervals over prolonged periods of time following addition of BIRD-2 or Scr. An example of the caspase 3/7 activity assay is included in Supplementary Figure S2. BIRD-2 treatment increased caspase $3 / 7$ activity compared with that observed with Scr treatment in H2171-RFP cells (Figure 3c), with results reaching statistical significance within $2-3 \mathrm{~h}$ of treatment $(P<0.05)$. BIRD-2 also induced time-dependent decreases in nuclear size in H2171-RFP cells (Figure $3 d$ ). Both of these findings are consistent with apoptosis induction. To provide more definitive morphological evidence 
a
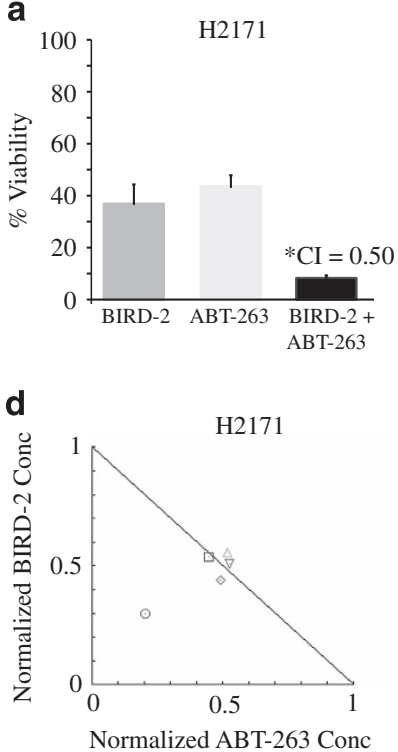

b
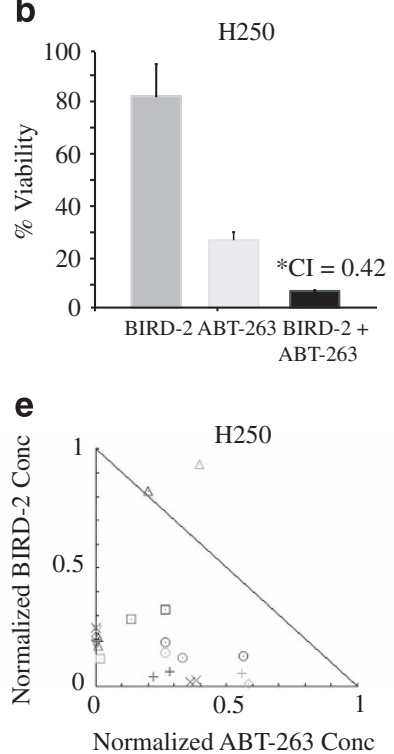

c
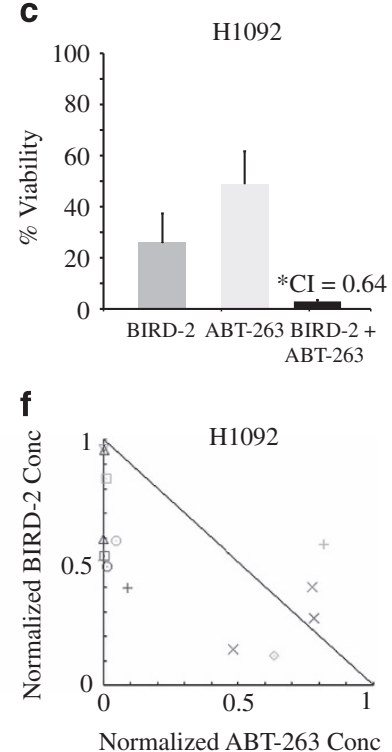

Figure 2 BIRD-2/ABT-263 synergy. (a-c) SCLC lines were treated with BIRD-2, ABT-263, or 127: 1 BIRD-2+ABT-263 as in Figure 1g, with cell viability determined by CTG assay. Error bars represent mean \pm S.D.; $N \geq 3$ experiments. Asterisk designates Chou-Talalay $\mathrm{Cl}$ calculated using the CompuSyn software, where $\mathrm{Cl}<1$ indicates synergy. (d-f) Normalized isobolograms for BIRD-2+ABT-263 combinations with plots generated using the CompuSyn software. Each symbol represents a unique combination of a given concentration of ABT-263 and a given concentration of BIRD-2. Symbols below the line indicate synergistic cytotoxicity; symbols on the lines indicate additive cytotoxicity; symbols above the lines indicate antagonism

of apoptosis, we examined Hoechst 33342-stained nuclei by fluorescence microscopy, detecting increased numbers of typical apoptotic nuclei in BIRD-2-treated cells compared with Scr peptide-treated cells (Figure 4). These findings indicate involvement of apoptosis in BIRD-2-induced cell death.

Our earlier work indicates that BIRD-2-mediated disruption of $\mathrm{Bcl}-2-\mathrm{IP}_{3} \mathrm{R}$ interaction induces marked, lethal elevation of cytoplasmic $\mathrm{Ca}^{2+}$ concentration in Bcl-2-positive lymphoid malignancies. ${ }^{26,29,32,35}$ BIRD-2 similarly induces a striking elevation of cytoplasmic $\mathrm{Ca}^{2+}$ in SCLC cells (Figure $5 a$ ), which is not observed in cells treated with Scr control peptide (Figure $5 b$ ). $\mathrm{Ca}^{2+}$ responses to BIRD-2 treatment were also much greater in SCLC cells than in NSCLC cells and normal epithelial cells (Figure 5c), consistent with the observation that BIRD-2 has less cytotoxic activity in these cells compared with SCLC cells (Figure 1f).

Pretreating cells with the intracellular $\mathrm{Ca}^{2+}$ chelator BAPTA-AM suppresses BIRD-2-induced $\mathrm{Ca}^{2+}$ elevation (Figure 5d), significantly decreasing BIRD-2-induced caspase activation (Figure 5e).

These findings suggest that BIRD-2 induces $\mathrm{Ca}^{2+}$-mediated apoptosis, as previously reported in lymphoid malignancies. $^{29,31,32}$ However, although we find BIRD-2 increases caspase activity in SCLC cells, the caspase inhibitors Z-VAD-fmk and Q-VD-OH did not suppress BIRD-2-induced cell death as measured by CTG assay or BIRD-2-induced apoptosis as measured by Hoechst-stained nuclear morphology (Supplementary Figure S3). These findings suggest that BIRD-2-induced $\mathrm{Ca}^{2+}$ elevation may induce apoptosis by a different mechanism in SCLC cells than in lymphoid cells.

Among the major known contributors to $\mathrm{Ca}^{2+}$-mediated apoptosis is activation of the $\mathrm{Ca}^{2+}$-dependent protease calpain. ${ }^{36}$ We find that the calpain inhibitor PD150606 37,38 decreases BIRD-2-induced loss of viability and apoptosis measured by the CTG assay (Figure 6a) and nuclear morphologilca changes, respectively (Figures $6 \mathrm{~b}$ and 7 ). Together, these findings indicate that BIRD-2-mediated disruption of $\mathrm{Bcl}-2-\mathrm{IP}_{3} \mathrm{R}$ interaction induces marked elevation of cytoplasmic $\mathrm{Ca}^{2+}$ in SCLC cells, triggering $\mathrm{Ca}^{2+}$-induced apoptosis mediated, at least in part, through calpain activation.

\section{Discussion}

Although $\mathrm{Bcl}-2$ promotes cell survival by two fully validated mechanisms, only the mechanism involving binding and inhibition of pro-apoptotic proteins is targeted for cancer treatment by the small-molecule BH3-mimetic ABT-263 (Figure 8). To test the potential value of targeting the mechanism involving $\mathrm{Bcl}-2$ interaction with $\mathrm{IP}_{3} \mathrm{Rs}$ in SCLC, we employed BIRD-2, a decoy peptide previously developed in our laboratory and found to induce $\mathrm{Ca}^{2+}$-mediated apoptosis in Bcl-2-positive lymphoid malignancies. ${ }^{29,31,32}$ We report here for the first time that BIRD-2 has single agent activity in SCLC, selectively inducing apoptosis in 13 of the 15 SCLC lines but not in NSCLC cells or normal lung epithelial cells.

For each of the 15 SCLC lines tested for BIRD-2 sensitivity, we also used the CTG assay to determine the relative sensitivity to ABT-263 (Supplementary Table S1). In vitro cellular sensitivity to ABT-263 has been defined as an IC50 level of $\leq 1 \mu \mathrm{M}$. $^{19}$ Following these criteria, nine of the SCLC lines tested are resistant to ABT-263. BIRD-2 induces cell death in six of these ABT-263-resistant lines (Supplementary Table S1). The demonstrated single-agent activity of BIRD-2 in ABT-263-resistant SCLC cells further supports the value of 
a



Annexin V-FITC



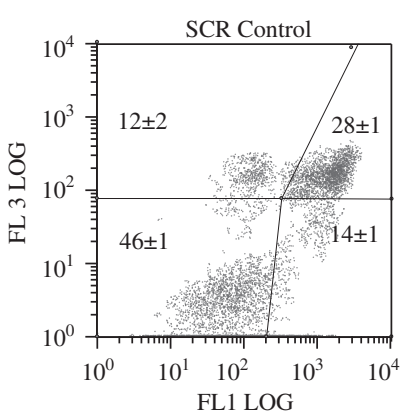


d



Figure 3 Biochemical evidence of apoptosis induction by BIRD-2. (a) Flow cytometry of Annexin $\mathrm{V}$ and propidium iodide-stained H2171 SCLC cells following treatment with $20 \mu \mathrm{M}$ BIRD-2 or Scr for $1 \mathrm{~h}$. (b) Bar graphs (mean \pm S.D., three experiments) quantifying the percentage of cells, treated, and analyzed as in panel (a), which are Annexin $\mathrm{V}$ positive but propidium iodide negative. (c) Quantification of caspase 3/7 activity in H2171-RFP cells by IncuCyte ZOOM at various time points following addition of $20 \mu \mathrm{M}$ BIRD-2 or Scr. (d) Measurements of nuclear area in H2171-RFP cells treated as in panel (c). Error bars represent mean \pm S.D., $N \geq 3$ experiments. ${ }^{*} P<0.05$. ${ }^{* \star} P<0.01$
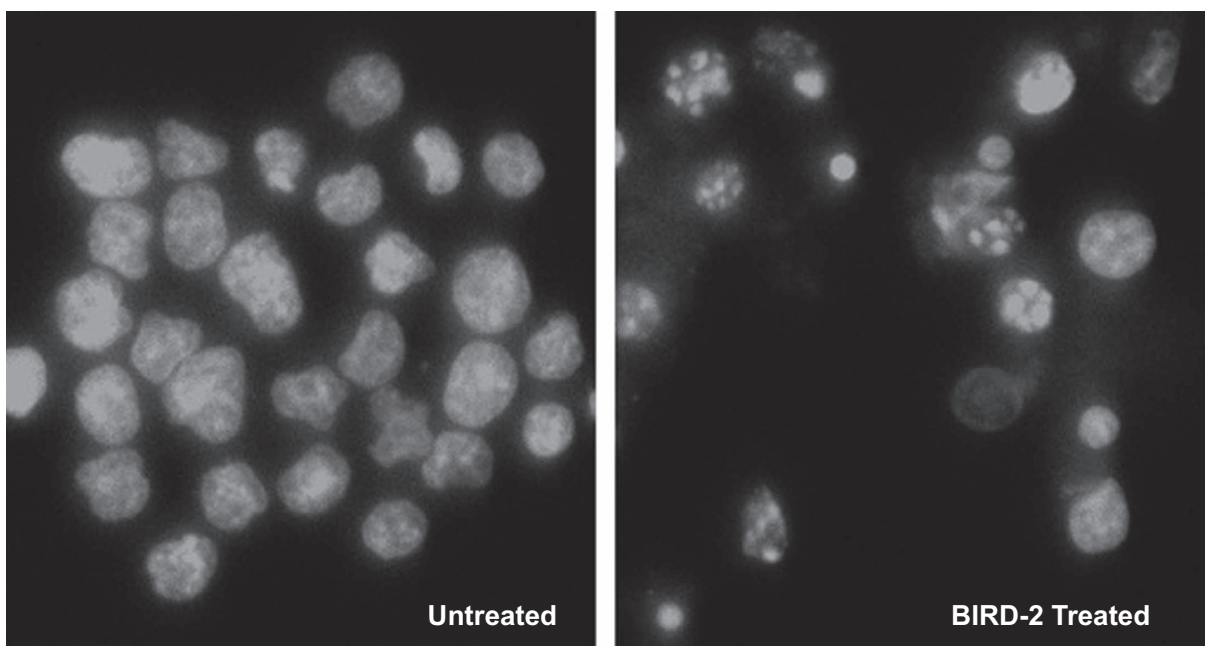

Figure 4 Morphological evidence of apoptosis induction by BIRD-2. H2171 SCLC cells were untreated (left) or treated for $48 \mathrm{~h}$ with $20 \mu \mathrm{M} \mathrm{BIRD-2} \mathrm{(right).} \mathrm{Nuclei} \mathrm{were} \mathrm{then}$ stained with Hoechst 33342, which fluoresces when bound to dsDNA. The nuclei of Scr-treated cells display a normal heterochromatin pattern, while the nuclei of many BIRD-2treated cells display chromatin condensation and apoptotic bodies typical of cells undergoing apoptosis

developing novel therapeutic agents that function similar to BIRD-2 by disrupting the $\mathrm{Bcl}-2-\mathrm{IP}_{3} \mathrm{R}$ interaction.

BIRD-2 and ABT-263 target distinctly different regions of the $\mathrm{Bcl}-2$ protein, thus inducing cell death by distinctly different mechanisms. BIRD-2 binds directly to the C-terminal $\mathrm{BH} 4$ domain of $\mathrm{Bcl}-2,{ }^{29,30,39}$ whereas $\mathrm{BH} 3$-mimetic agents bind to a hydrophobic region of $\mathrm{Bcl}-2$ composed of $\mathrm{BH}$ domains $1-3 .{ }^{13-15} \mathrm{BH} 3-$ mimetic agents induce apoptosis by displacing pro-apoptotic $\mathrm{BH} 3-$ only proteins (e.g., Bim) from Bcl-2, ${ }^{13-15}$ whereas BIRD-2 does not alter Bcl-2's binding of these pro-apoptotic proteins. ${ }^{28}$ Conversely, BIRD-2 induces $\mathrm{Ca}^{2+}$-mediated apoptosis, whereas we have previously shown that $A B T-263$ does not alter Bcl-2 interaction with $\mathrm{IP}_{3} \mathrm{Rs}$ and does not induce $\mathrm{Ca}^{2+}$ elevation. ${ }^{29}$ Ultimately, these targeting approaches work in parallel to induce apoptosis by reversing separate Bcl-2-mediated pro-survival mechanisms. Thus 

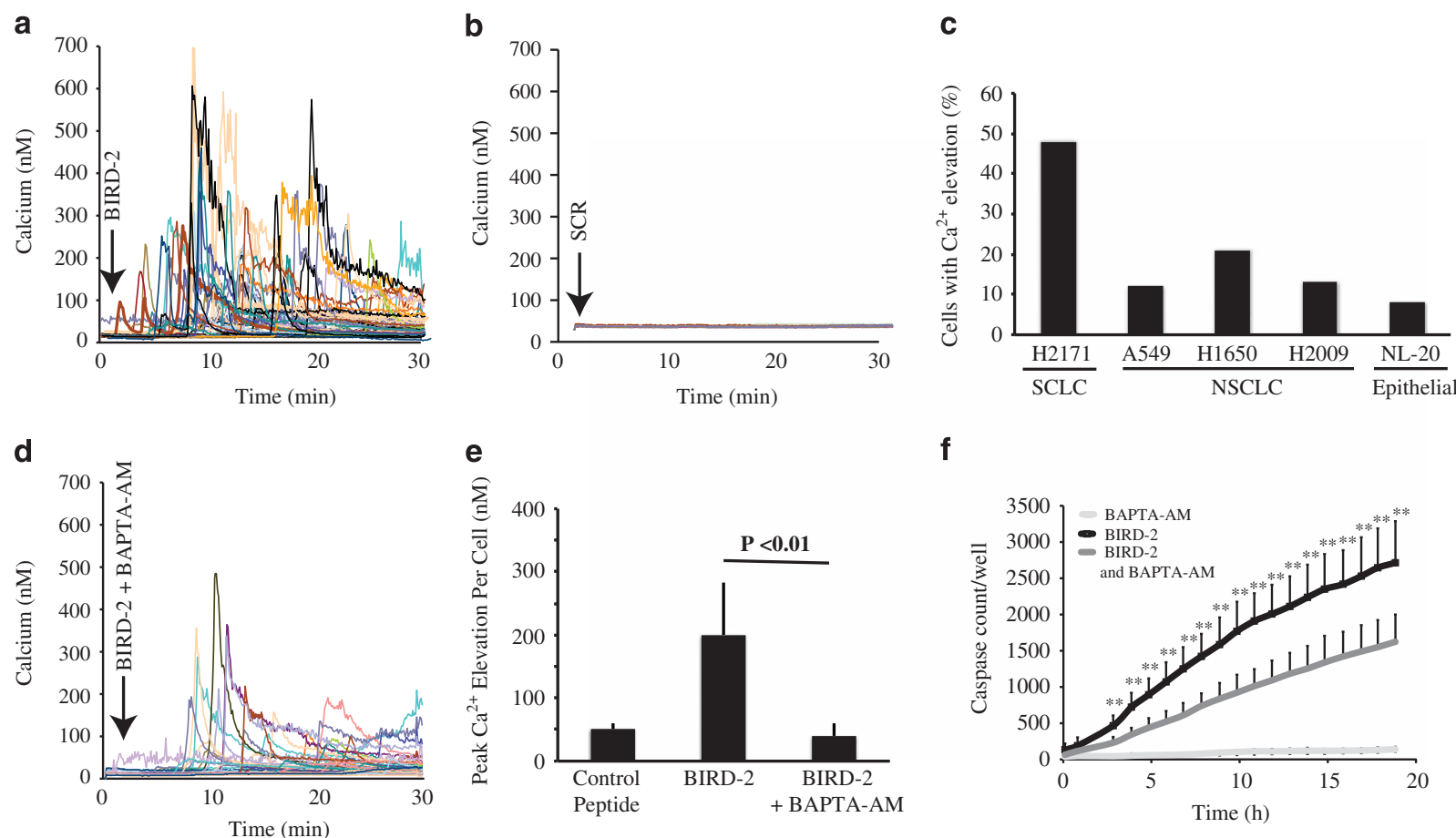

Figure 5 BIRD-2-induced $\mathrm{Ca}^{2+}$ elevation and $\mathrm{Ca}^{2+}$-mediated caspase activation. (a) Shown are continuous single-cell recordings of cytoplasmic $\mathrm{Ca}^{2+}$ by digital imaging performed simultaneously in $65 \mathrm{H} 2171 \mathrm{SCLC}$ cells following addition of $10 \mu \mathrm{M} \mathrm{BIRD-2}$ (arrow). Traces represent $\mathrm{Ca}^{2+}$ levels in individual cells. (b) Same as panel (a) except in Scr-treated H2171cells. (c) Bar graph represents the percentage of SCLC, NSCLC, and normal lung epithelial cell lines responding to BIRD-2 with a significant elevation of cytoplasmic $\mathrm{Ca}^{2+}$ above basal $\mathrm{Ca}^{2+}$ levels. Cytoplasmic $\mathrm{Ca}^{2+}$ was measured as in panel (a). This figure summarizes a single experiment analyzing $>80 \mathrm{cells}$ in each cell line; shown is the average peak cytoplasmic $\mathrm{Ca}^{2+}$ elevation in each cell line within 30 min following addition of $5 \mu \mathrm{M} \mathrm{BIRD-2}$. (d) Cytoplasmic $\mathrm{Ca}^{2+}$ was recorded as in panel (a) except that $\mathrm{H} 2171$ cells were pretreated $1 \mathrm{~h}$ before adding $10 \mu \mathrm{M}$ BIRD-2 with $5 \mu \mathrm{M}$ BAPTA-AM to chelate intracellular $\mathrm{Ca}^{2+}$ and thus block cytoplasmic $\mathrm{Ca}^{2+}$ elevation. (e) Shown is a bar graph representing the peak cytoplasmic $\mathrm{Ca}^{2+}$ elevation (mean \pm S.D., three experiments) induced by $10 \mu \mathrm{M}$ BIRD-2 treatment, with or without $10 \mu \mathrm{M}$ BAPTA-AM pretreatment. Results indicate that BAPTA-AM pretreatment inhibits BIRD-2-induced $\mathrm{Ca}^{2+}$ elevation. (f) BAPTA-AM pretreatment decreases BIRD-2-mediated caspase 3/7 induction, measured by IncuCyteZOOM as in Figure 3c. Experiments in panels $\mathbf{d - f}$ were performed at least three times, using 2-5 $\mu$ M BAPTA-AM and 15-20 $\mu$ M BIRD-2. Error bars in panel (e) represent mean \pm S.D., $N=85$ cells. ${ }^{*} P<0.01$

combinations of BIRD-2 and ABT-263, as shown here, are often synergistic rather than additive. As synergy between the two compounds was most evident in 6 of the 15 SCLC lines tested, additional yet-to-be-determined factors may influence the efficacy of the ABT-263 and BIRD-2 combination.

The nature of Bcl-2's control over intracellular $\mathrm{Ca}^{2+}$ has been the subject of extensive investigation and is important for predicting how disruption of $\mathrm{Bcl}-2-\mathrm{IP}_{3} \mathrm{R}$ interaction may potentially affect normal cell function. BIRD-2 does not kill various types of normal cells, including normal human peripheral blood lymphocytes, ${ }^{29}$ normal mouse embryonic fibroblasts (F Zhong and C Distelhorst, unpublished), and normal lung epithelial cells (Figure 1f). Moreover, $\mathrm{Bcl}-2$ does not inhibit normal physiological $\mathrm{Ca}^{2+}$ signals but selectively represses high-amplitude $\mathrm{Ca}^{2+}$ elevations capable of inducing apoptosis. ${ }^{26,39}$ We speculate that the latter property of Bcl-2 is key to exploitation of $\mathrm{Bcl}-2$ by cancer cells, as $\mathrm{Bcl}-2$ would allow $\mathrm{Ca}^{2+}$-mediated growth signals while blocking proapoptotic $\mathrm{Ca}^{2+}$ elevation, thereby promoting cancer cell survival.

In recent studies in Bcl-2-positive lymphoid malignancies, we found that the caspase inhibitor Z-VAD-fmk inhibits BIRD-2-induced apoptosis. ${ }^{31}$ In the present work, however, two caspase inhibitors, Z-VAD-fmk and q-VD-OH, did not inhibit BIRD-2-induced death of SCLC cells. Apoptosis, including $\mathrm{Ca}^{2+}$-induced apoptosis, is known to occur by both capspase-dependent and -independent mechanisms. ${ }^{36}$ In addition, $\mathrm{Ca}^{2+}$ elevation activates a variety of targets involved in mediating $\mathrm{Ca}^{2+}$-induced cell death. ${ }^{36} \mathrm{Ca}^{2+}$-induced apoptosis in certain cell types is mediated by members of the calpain family of $\mathrm{Ca}^{2+}$-activated cysteine proteases. ${ }^{36,40}$ Here we find that the calpain inhibitor PD150606 inhibits BIRD-2 induction of apoptosis in SCLC cells. Collectively, therefore, our findings in lymphoid malignancies and the solid tumor, SCLC, indicate that although BIRD-2 elevates $\mathrm{Ca}^{2+}$ levels in these different cell types, the signaling pathways leading to apoptosis appear to be different.

The current findings suggest SCLC cell survival depends in part on intracellular $\mathrm{Ca}^{2+}$ regulation by the $\mathrm{Bcl}-2-\mathrm{IP}_{3} \mathrm{R}$ interaction. Interestingly, a recent bioinformatic screen to identify SCLC-repositioning hits identified $\mathrm{Ca}^{2+}$ signaling pathways among the top three hits. ${ }^{41}$ These findings, along with the findings reported here, highlight the relevance of altered $\mathrm{Ca}^{2+}$ homeostasis and signaling in SCLC. Moreover, there is considerable evidence that $\mathrm{Ca}^{2+}$ signaling and $\mathrm{Ca}^{2+}$ signaling checkpoints are remodeled in cancer cells, in part through altered regulation of $\mathrm{IP}_{3} \mathrm{Rs}$, enhancing cell proliferation and survival. ${ }^{42,43}$ 
a

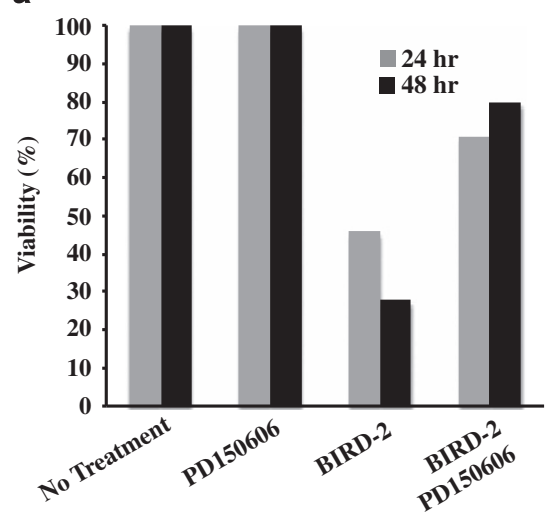

b

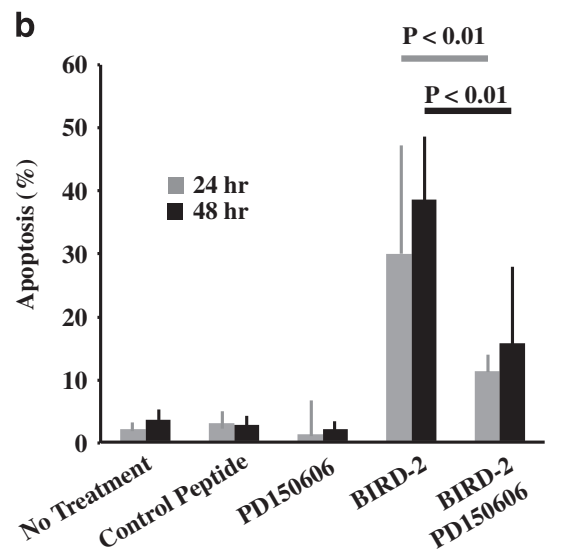

Figure 6 Effect of calpain inhibition on BIRD-2-induced cell death. (a) Bar graphs represent the percentage of viable H2171 cells, measured by CTG assay, at 24 and $48 \mathrm{~h}$ after various treatments as designated. Concentrations of BIRD-2 and the calpain inhibitor PD150606 were each $20 \mu \mathrm{M}$. Results represent the mean of triplicate determinations in a single experiment and suggest that PDI150606 inhibits BIRD-2-induced cell death. (b) Bar graph represents the percentage of apoptotic cells, based on fluorescence microscopic detection of apoptotic nuclear morphology in H2171 cells stained with Hoechst 33342. Bars represent mean \pm S.D. of six images; in each image, an average of 46 cells were analyzed. This experiment was repeated twice with the same result
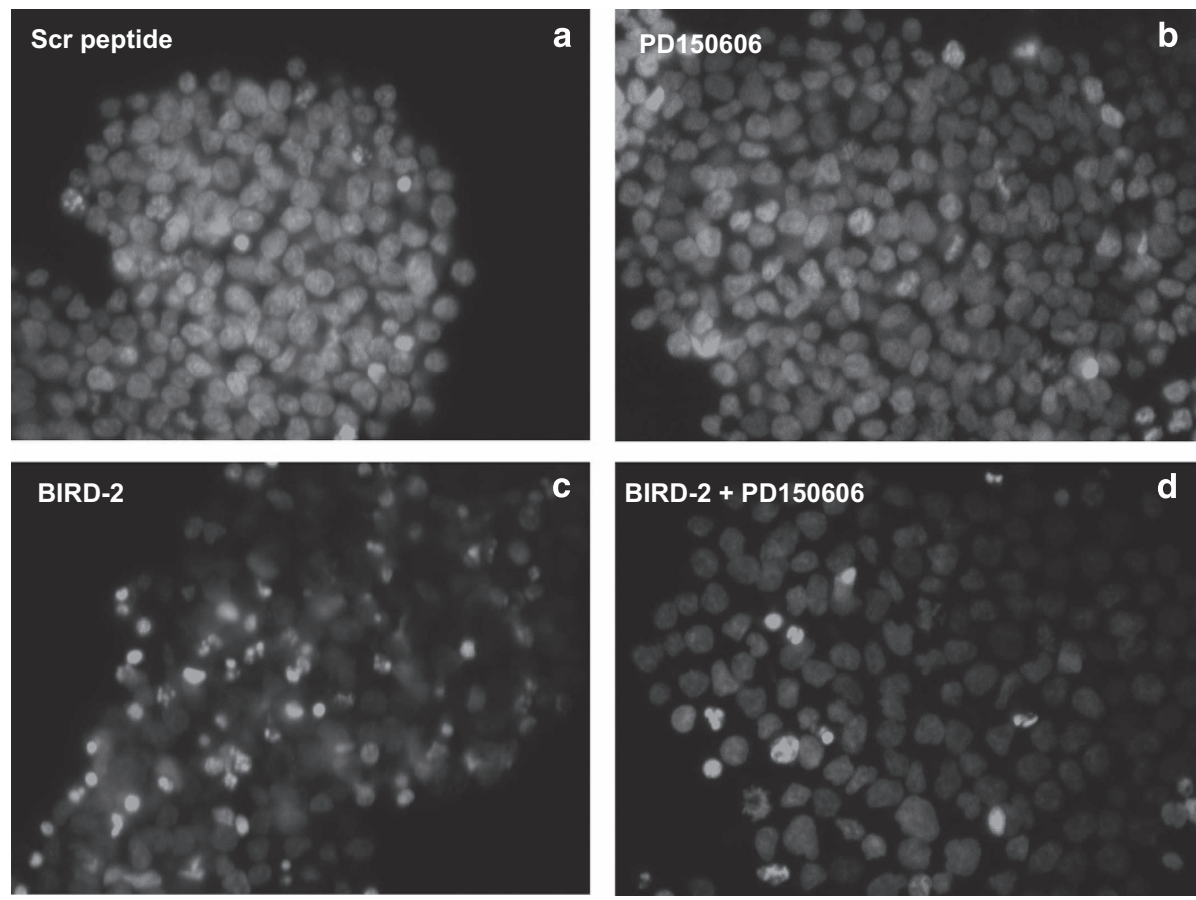

Figure 7 Effect of calpain inhibition on BIRD-2-induced apoptosis. Shown are representative images from Figure 6b illustrating inhibition of BIRD-2-induced apoptosis by PK150606 in Hoechst 33342-stained H2171 cells. Cells were treated for $48 \mathrm{~h}$ as in Figure 6 with: (a) $20 \mu \mathrm{M}$ control peptide, (b) $20 \mu \mathrm{M}$ PD150606, (c) $20 \mu \mathrm{M}$ BIRD-2, (d) $20 \mu \mathrm{M}$ BIRD-2 + 20 M PD150606

BIRD-2 is effective at low-micromolar concentrations, which are achievable by peptides in vivo. ${ }^{44}$ Although unmodified peptides are viable clinical candidates, peptides have a number of undesirable characteristics, including susceptibility to protease cleavage, limited bioavailability, incomplete cellular uptake, and potential off-target effects. $^{44,45}$ The novel technology of peptide stapling has been shown to dramatically increase both in vitro and in vivo peptide biological activity. ${ }^{46,47}$ Future directions include inserting hydrocarbon staples into BIRD-2 to support its further clinical development. Small-molecule inhibitors of the $\mathrm{Bcl}-2-\mathrm{IP}_{3} \mathrm{R}$ interaction may also be sought in order to circumvent the potential shortcomings of unmodified peptides. A recent report of a small-molecule $\mathrm{Bcl}-2$ $\mathrm{BH} 4$ domain antagonist that may kill lung cancer cells, at least in part, by inhibiting $\mathrm{Bcl}-2-\mathrm{IP}_{3} \mathrm{R}$ interaction suggests the feasibility of such an approach. ${ }^{48}$ Ultimately, it is hoped that actual therapeutic agents can be developed based on the proof-of-principle evidence and patterned after BIRD-2. 


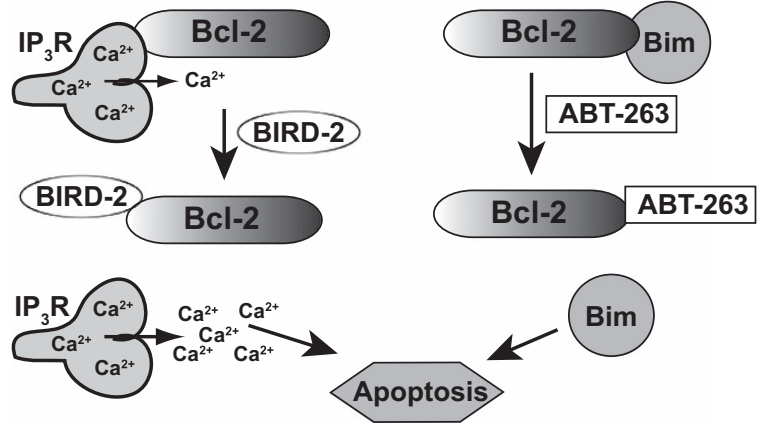

Figure 8 Diagram illustrating Bcl-2's dual antiapoptotic mechanisms and their differential targeting by BIRD-2 and $A B T-263$. Left, $B c-2$ binds to the $\mathbb{P}_{3} R$, preventing pro-apoptotic $\mathrm{Ca}^{2+}$ elevation. BIRD-2 inhibits this interaction, inducing apoptosis by releasing high levels of $\mathrm{Ca}^{2+}$ from the ER into the cytoplasm. Right, by binding $\mathrm{BH} 3$-only proteins such as Bim, Bcl-2 prevents Bim from activating executioner proteins such as Bax/Bak. BH3-mimetic agents such as ABT-263 block this interaction, thereby freeing Bim to trigger apoptosis

\section{Materials and Methods}

Cell lines. SCLC, NL-20, and NSCLC cell lines were purchased from the American Type Culture Collection (ATCC, Manassas, VA, USA) with the exception of the H250 SCLC line, which was purchased from Sigma-Aldrich (St. Louis, MO, USA). The cell lines were acquired within the past 3 years and used at a passage number $<10$. These cell lines were not authenticated because of their direct purchase from ATCC and Sigma-Aldrich and low passage number. H2171, H1694, DMS454, H1048, SW1271, NL-20, H1650, H2009, and A549 cells were grown in 1:1 DMEM/F12 supplemented with $8 \%$ fetal bovine serum and $2 \mathrm{mM}$ GlutaMax (Gibco Life Technologies, Grand Island, NY, USA). H378, DMS79, H250, H446, $\mathrm{H} 82, \mathrm{H} 526$, and $\mathrm{H} 1688$ cells were grown in RPMI- 1640 medium, supplemented with $8 \%$ fetal bovine serum and $2 \mathrm{mM}$ GlutaMax. H1092, H2029, and H64 cells were grown in 1:1 DMEM/F12 supplemented with $5 \%$ fetal bovine serum, $2 \mathrm{mM}$ GlutaMax, $10 \mathrm{nM}$ hydrocortisone, $0.005 \mathrm{mg} / \mathrm{ml}$ insulin, $0.01 \mathrm{mg} / \mathrm{ml}$ transferrin, $10 \mathrm{nM}$ beta-estradiol, and $30 \mathrm{nM}$ sodium selenite.

Reagents. ABT-263 was purchased from Selleck Chemicals (Houston, TX, USA). CTG was from Promega Life Sciences (Madison, WI, USA). AlamarBlue, Hoechst 33342, Fura-2-AM, and Alexa Fluor 488 Annexin V solution were from ThermoFisher (Pittsburgh, PA, USA). PD150606 was from Sigma-Aldrich. Z-VADFMK was purchased from Enzo Life Sciences (Farmingdale, NY, USA) and q-VD$\mathrm{OH}$ was a generous gift of Shigemi Matsuyama at Case Western Reserve University, Cleveland, OH, USA.

Peptides. The peptide BIRD-2 (RKKRRQRRRGGNVYTEIKCNSLLPLAAIVRV) and the scrambled peptide control, Scr (RKKRRQRRRGGDLNEVTCSLIVDRINPVKLY), were synthesized by GenScript (Piscataway, NJ, USA). These peptides are described in detail elsewhere. ${ }^{29}$ In these peptides, the sequence RKKRRQRRRGG corresponds to the cell-penetrating peptide of HIV TAT, used to mediate peptide uptake into cells. Peptides were purified by liquid chromatography/ mass spectrometry to $>95 \%$ purity and were quantified by amino-acid analysis.

Cell viability. Cell lines were cultured in T75 flasks to approximately 50\% confluency. Adherent cell lines were then trypsinized. Cells were suspended in fresh growth media, plated in 96-well plates at $10000 \mathrm{cells} /$ well, and allowed to settle overnight at $37^{\circ} \mathrm{C}$. Cells were then treated for various periods of time and with various concentrations $(0.4-200 \mu \mathrm{M})$ of either BIRD-2 or Scr, as stated under Results section. Viability was determined using either the CTG or AlamarBlue viability assays. Dose-response curves were generated in Microsoft Excel (Microsoft, Redmond, WA, USA); cell-death IC50 values were calculated using the GraphPad Prism Statistical Software (La Jolla, CA, USA). Experiments were performed in triplicate; error bars represent S.D.

For CTG viability experiments, SCLC cells were added to 96-well plates and treated as above. At time points designated under Results section, CTG assay reagent (Promega) was diluted five-fold in PBS, and $80 \mu$ l of the diluted reagent was added to each well. Plates were agitated for $2 \mathrm{~min}$ and then incubated at rest for
$10 \mathrm{~min}$. Total luminescence of each well, corresponding to ATP content, was recorded using a VICTOR3 Microplate reader (PerkinElmer, Akron, OH, USA).

To confirm the validity of the CTG assay as a surrogate for cell viability in SCLC cells, the AlamarBlue viability assay was performed in parallel in a number of experiments. For the AlamarBlue assay, SCLC cells were added to 96-well plates and treated as above. Eight $\mu \mathrm{L}$ of AlamarBlue reagent (Life Technologies, Grand Island, NY, USA) was added to each well, mixed thoroughly, and allowed to incubate at $37^{\circ} \mathrm{C}$ for 2-4 h. Fluorescence values of each well, corresponding to the reductive capacity of the cell, were generated using an Envision-2103 Microplate reader (PerkinElmer) with an excitation filter of $560 \mathrm{~nm}$ and an emission filter of $590 \mathrm{~nm}$.

Synergy determination. Following the Chou-Talalay method, ${ }^{34}$ IC50 values for BIRD-2 and ABT-263 were first assessed in SCLC cell lines by CTG assay. Ten thousand SCLC cells were then added to each well of a 96-well plate and were treated for $48 \mathrm{~h}$ with serial dilutions of BIRD-2 and ABT-263. In the H2171 cell line, BIRD-2 and ABT-263 were combined at maximum doses equal to four times their individual IC50s and then serially diluted at a constant BIRD-2:ABT-263 ratio. Serial dilutions of ABT-263, BIRD-2, Scr, and $\mathrm{H}_{2} \mathrm{O}$ alone were included as controls. Viability data were generated using the CTG assay as described above. $\mathrm{Cl}$ values were generated using the CompuSyn software; synergy was defined as a $\mathrm{Cl}<1$, according to Chou-Talalay method. ${ }^{34}$

Flow cytometry. Flow cytometry was used to measure apoptosis according to externalization of phosphatidylserine, detected by Annexin V, and to simultaneously measure increased membrane permeability, detected by propidium iodide uptake. Five hundred thousand SCLC cells were added to 35-mm dishes and treated for $1 \mathrm{~h}$ with BIRD-2 or Scr. Cells were then harvested, washed in PBS, and stained for $15 \mathrm{~min}$ in the dark with a 30-fold dilution of Alexa Fluor 488 Annexin V solution and $1 \mu \mathrm{g} / \mathrm{ml}$ propidium iodide. Stained samples were diluted $5 x$ in annexin-binding buffer. Samples were analyzed in the Case Comprehensive Cancer Center Cytometry Core Facility on an EPICS-XL flow cytometer (Beckman Coulter, Pasadena, CA, USA). Data analysis was performed using WinList (Verity House Software, Topsham, ME, USA).

IncuCyte ZOOM. IncuCyte ZOOM (Essen Biosciences, Ann Arbor, MI, USA) was used to detect caspase activation and nuclear condensation as described by others. ${ }^{49}$ The CellPlayer NucLight Red lentiviral construct (Essen Biosciences) was inserted into H2171, SW1271, and H1092 SCLC cells (hereafter referred to as H2171-RFP, SW1271-RFP, and H1092-RFP cells), using their standard infection protocol. The H2171-RFP, SW1271-RFP, and H1092-RFP cell lines were maintained in $0.5 \mu \mathrm{g} / \mathrm{ml}$ puromycin to select for RFP-infected cells. Successful insertion of the NucLight Red lentiviral construct was confirmed via direct visualization of transfected cells on the IncuCyte ZOOM fluorescent microscope. For IncuCyte ZOOM experiments, H2171-RFP, SW1271-RFP, and/or H1092-RFP SCLC cells were suspended in fresh growth media, plated in 96-well plates at 10000 cells/well, and allowed to settle overnight at $37^{\circ} \mathrm{C}$. Caspase $3 / 7$ activity was assessed using the Essen Biosciences IncuCyte ZOOM caspase 3/7 assay, as described previously. ${ }^{49}$ Briefly, the CellPlayer 96-Well Kinetic Caspase 3/7 Reagent (designated hereafter as caspase $3 / 7$ reagent) consists of an inert peptide, a caspase 3/7 recognition site, and the peptide NucView 488 (Essen Biosciences). The full-length caspase $3 / 7$ reagent is non-fluorescent and is confined to the cytoplasm. Upon induction of apoptosis, caspase $3 / 7$ cleaves the bond between the inert peptide and NucView 488. Liberated NucView 488 has a high affinity for nuclear DNA and is fluorescent in the green spectrum; thus caspase $3 / 7$ activation correlates with an increase in fluorescent green nuclei. To assess nuclear condensation, SCLC cells were cultured in 96-well plates and monitored in the IncuCyte ZOOM acquiring images every $2 \mathrm{~h}$ following treatment with ABT-263, BIRD-2, or Scr control peptide. Average areas of RFP-labeled nuclei were determined at each time point using the IncuCyte ZOOM analysis software.

Apoptotic morphology. Apoptotic nuclear morphology was evaluated in wild-type (i.e., RFP-negative) SCLC cells stained with Hoechst $33342(10 \mu \mathrm{g} / \mathrm{ml})$ for $15 \mathrm{~min}$ at $37^{\circ} \mathrm{C}$ and visualized by epifluorescence microscopy (Photo Technology International EasyRatio Pro imaging platform, Photon Technology International, London, Ontario, Canada) equipped with dual excitation and emission capability and excitation wavelength selection by monochromater. Images were recorded using a Zeiss Axio ObservervA1 inverted microscope with $\times 40$ fluor oil objective (Carl Zeiss Microscopy, Thornwood, NY, USA) and Roper CoolSnap digital camera (Photometrics, Tucson, AX, USA). 
Calcium measurement. Techniques for single-cell digital imaging of Fura-2-AM-loaded cells are described previously. ${ }^{29}$

Statistical methods. Single-agent caspase $3 / 7$ experiments were performed in octuplicate (4 images/well $\times 2$ wells); error bars correspond to 1 S.D. The $P$-values were generated via the GraphPad Prism statistical software, using unpaired $t$-tests to compare $\mathrm{H}_{2} \mathrm{O}$ versus BIRD-2, $\mathrm{H}_{2} \mathrm{O}$ versus $\mathrm{Scr}$, and BIRD-2 versus Scr. Dual-agent caspase 3/7 experiments were performed in 48-plicate ( 4 images/well $\times 12$ wells); error bars correspond to S.D. Unpaired $t$-tests compared treatment with BIRD-2 and ABT-263 versus BIRD-2 alone. All other biochemical and cellular assays had a sample size of three replicates for each comparison of experimental versus control conditions. This sample size determination was based on the following experimental constraints: a power of 0.80 ; expected S.D. of $\pm 10 \%$ maximum value; powered to detect differences of $\pm 25 \%$ maximum value, and type 1 error rate ( $P$-value) of 0.05 . Average values and S.Ds. were calculated using Microsoft Excel. The IC50 of dose-response curves was generated by using the GraphPad Prism software to fit data to a 'nonlinear regression: log(inhibitor) versus response-variable slope' model. $P$-values were calculated for all experiments using th GraphPad Prism software to conduct unpaired $t$-tests between experimental and control conditions. Statistically significant differences were defined as those with $P<0.05$ between experimental and control conditions. Power and sample size estimations were calculated using the GraphPad StatMate software: http://graphpad. com/scientific-software/statmate/. For all cellular assays, 5000-10 000 SCLC cells were used per experimental condition tested.

\section{Conflict of Interest}

The authors declare no conflict of interest.

Acknowledgements. We thank John Pink for providing guidance and feedback in synergy calculations and Michael Sramkoski for sharing his expertise in flow cytometric analysis. We also thank Andrew Lavik for providing technical guidance and assistance in manuscript preparation. This work was supported by NIH grants RO1 CA085804 (to CWD), T32 CA059366 (to EFG), and 2P30 CA043703 (to AD) Additional funding is from Case Western Reserve University and University Hospitals Seidman Cancer Center (to AD). EFG was supported by the Case Department of Medicine at MetroHealth Medical Center Physician Scientist Pathway.

1. Chute JP, Chen T, Feigal E, Simon R, Johnson BE. Twenty years of phase III trials fo patients with extensive-stage small-cell lung cancer: perceptible progress. J Clin Oncol 1999; 17: $1794-1801$

2. Govindan R, Page N, Morgensztern D, Read W, Tierney R, Vlahiotis A et al. Changing epidemiology of small-cell lung cancer in the United States over the last 30 years: analysis of the surveillance, epidemiologic, and end results database. J Clin Oncol 2006; 24 4539-4544.

3. van Meerbeeck JP, Fennell DA, De Ruysscher DK. Small-cell lung cancer. Lancet 2011; 378 1741-1755.

4. American Cancer Society. Cancer Facts and Figures, ACS, 2014

5. William WN Jr., Glisson BS. Novel strategies for the treatment of small-cell lung carcinoma. Nat Rev Clin Oncol 2011; 8: 611-619.

6. Chan BA, Coward Jl. Chemotherapy advances in small-cell lung cancer. J Thorac Dis 2013; 5(Suppl 5): S565-S578

7. Ikegaki N, Katsumata M, Minna J, Tsujimoto $Y$. Expression of bcl-2 in small cell lung carcinoma cells. Cancer Res 1994; 54: 6-8

8. Tsujimoto Y, Finger LR, Yunis J, Nowell PC, Croce CM. Cloning of the chromosome breakpoint of neoplastic B cells with the $t(14 ; 18)$ chromosome translocation. Science 1984 226: 1097-1099.

9. Kaiser U, Schilli M, Haag U, Neumann K, Kreipe H, Kogan E et al. Expression of bcl-2protein in small cell lung cancer. Lung Cancer 1996; 15: 31-40.

10. Lawson MH, Cummings NM, Rassl DM, Vowler SL, Wickens M, Howat WJ et al. Bcl-2 and beta1-integrin predict survival in a tissue microarray of small cell lung cancer. $\mathrm{Br} J$ Cancer 2010; 103: 1710-1715.

11. Hodgkinson CL, Morrow CJ, Li Y, Metcalf RL, Rothwell DG, Trapani F et al. Tumorigenicity and genetic profiling of circulating tumor cells in small-cell lung cancer. Nat Med 2014; 20: 897-903.

12. Byers LA, Wang J, Nilsson MB, Fujimoto J, Saintigny $P$, Yordy J et al. Proteomic profiling identifies dysregulated pathways in small cell lung cancer and novel therapeutic targets including PARP1. Cancer Discov 2012; 2: 798-811.

13. Chipuk JE, Moldoveanu T, Llambi F, Parsons MJ, Green DR. The BCL-2 family reunion. Mol Cell 2010; 37: 299-310.
14. Czabotar PE, Lessene G, Strasser A, Adams JM. Control of apoptosis by the BCL-2 protein family: implications for physiology and therapy. Nat Rev Mol Cell Biol 2014; 15: 49-63.

15. Correia C, Lee SH, Meng XW, Vincelette ND, Knorr KL, Ding $\mathrm{H}$ et al. Emerging understanding of $\mathrm{Bcl}-2$ biology: implications for neoplastic progression and treatment. Biochim Biophys Acta 2015; 1853: 1658-1671.

16. Billard C. BH3 mimetics: status of the field and new developments. Mol Cancer Ther 2013; 12: $1691-1700$

17. Anderson MA, Huang $D$, Roberts $A$. Targeting BCL2 for the treatment of lymphoid malignancies. Semin Hematol 2014; 51: 219-227.

18. Vogler M. Targeting Bcl-2 proteins for the treatment of solid tumours. Adv Med 2014; 204: $1-14$.

19. Oltersdorf T, Elmore SW, Shoemaker AR, Armstrong RC, Augeri DJ, Belli BA et al. An inhibitor of Bcl-2 family proteins induces regression of solid tumours. Nature 2005; 435 : 677-681.

20. Gandhi L, Camidge DR, Ribeiro de Oliveira M, Bonomi P, Gandara D, Khaira D et al. Phase I study of Navitoclax (ABT-263), a novel Bcl-2 family inhibitor, in patients with small-cell lung cancer and other solid tumors. J Clin Oncol 2011; 29: 909-916.

21. Zhu W, Cowie A, Wasfy GW, Penn LZ, Leber B, Andrews DW. Bcl-2 mutants with restricted subcellular location reveal spatially distinct pathways for apoptosis in different cell types. EMBO J 1996; 15: 4130-4141.

22. Annis MG, Yethon JA, Leber B, Andrews DW. There is more to life and death than mitochondria: Bcl-2 proteins at the endoplasmic reticulum. Biochim Biophys Acta 2004; 1644: 115-123.

23. Thomenius MJ, Wang NS, Reineks EZ, Wang Z, Distelhorst CW. Bcl-2 on the endoplasmic reticulum regulates Bax activity by binding to BH3-only proteins. J Biol Chem 2003; 278: 6243-6250.

24. Chen R, Valencia I, Zhong F, McColl KS, Roderick HL, Bootman MD et al. Bcl-2 functionally interacts with inositol 1,4,5-trisphosphate receptors to regulate calcium release from the ER. J Cell Biol 2004; 166: 193-203.

25. Hanson CJ, Bootman MD, Distelhorst CW, Wojcikiewicz RJ, Roderick HL. Bcl-2 suppresses $\mathrm{Ca}^{2+}$ release through inositol 1,4,5-trisphosphate receptors and inhibits $\mathrm{Ca}^{2+}$ uptake by mitochondria without affecting ER calcium store content. Cell Calcium 2008; 44: 324-338.

26. Chang MJ, Zhong F, Lavik AR, Parys JB, Berridge MJ, Distelhorst CW. Feedback regulation mediated by Bcl-2 and DARPP-32 regulates inositol 1,4,5-trisphosphate receptor phosphorylation and promotes cell survival. Proc Natl Acad Sci USA 2014; 111: 1186-1191.

27. Rong Y, Bultynck G, Aromolaran AS, Zhong F, Parys JB, De Smedt $\mathrm{H}$ et al. The BH4 domain of Bcl-2 inhibits ER calcium release and apoptosis by binding the regulatory and coupling domain of the IP3 receptor. Proc Natl Acad Sci USA 2009; 106: 14397-14402.

28. Rong Y, Aromolaran AS, Bultynck G, Zhong F, Li X, McColl KS et al. Targeting Bcl-2-IP3 receptor interaction to reverse Bcl-2's inhibition of apoptotic calcium signals. Mol Cell 2008; 31: 255-265.

29. Zhong F, Harr MW, Bultynck G, Monaco G, Parys JB, DeSmedt $\mathrm{H}$ et al. Induction of $\mathrm{Ca}^{2+}$-driven apoptosis in chronic lymphocytic leukemia cells by peptide-mediated disruption of Bcl-2-IP receptor interaction. Blood 2011; 117: 2924-2934.

30. Monaco G, Decrock E, Nuyts K, Wagner LE 2nd, Luyten T, Strelkov SV et al. Alpha-helical destabilization of the Bcl-2-BH4-domain peptide abolishes its ability to inhibit the $\mathrm{IP}_{3}$ receptor. PLoS One 2013; 8: e73386.

31. Lavik AR, Zhong F, Chang MJ, Greenberg E, Choudhary Y, Smith MR et al. A synthetic peptide targeting the $\mathrm{BH} 4$ domain of $\mathrm{Bcl}-2$ induces apoptosis in multiple myeloma and follicular lymphoma cells alone or in combination with agents targeting the $\mathrm{BH}$-binding pocket of Bcl-2. Oncotarget 2015; 6: 27388-27402.

32. Akl H, Monaco $G$, La Rovere $R$, Welkenhuyzen $K$, Kiviluoto $S$, Vervliet T et al. IP3R2 levels dictate the apoptotic sensitivity of diffuse large $B$-cell lymphoma cells to an $\mathbb{I P}_{3} R$-derived peptide targeting the BH4 domain of Bcl-2. Cell Death Dis 2013; 4: e632.

33. Tse C, Shoemaker AR, Adickes J, Anderson MG, Chen J, Jin S et al. ABT-263: a potent and orally bioavailable Bcl-2 family inhibitor. Cancer Res 2008; 68: 3421-3428.

34. Chou TC. Drug combination studies and their synergy quantification using the ChouTalalay method. Cancer Res 2010; 70: 440-446.

35. Monaco G, Decrock E, Akl H, Ponsaerts R, Vervliet T, Luyten T et al. Selective regulation of $\mathrm{IP}(3)$-receptor-mediated $\mathrm{Ca}(2+)$ signaling and apoptosis by the $\mathrm{BH} 4$ domain of $\mathrm{Bcl}-2$ versus Bcl-Xl. Cell Death Differ 2012; 19: 295-309.

36. Zhivotovsky B, Orrenius S. Calcium and cell death mechanisms: a perspective from the cell death community. Cell Calcium 2011; 50: 211-221.

37. Norberg E, Karlsson M, Korenovska O, Szydlowski S, Silberberg G, Uhlen P et al. Critical role for hyperpolarization-activated cyclic nucleotide-gated channel 2 in the AIF-mediated apoptosis. EMBO J 2010; 29: 3869-3878.

38. Low KE, Karunan Partha S, Davies PL, Campbell RL. Allosteric inhibitors of calpains: reevaluating inhibition by PD150606 and LSEAL. Biochim Biophys Acta 2014; 1840: 3367-3373.

39. Zhong F, Davis MC, McColl KS, Distelhorst CW. Bcl-2 differentially regulates $\mathrm{Ca}^{2+}$ signals according to the strength of T cell receptor activation. J Cell Biol 2006; 172: 127-137.

40. Vanags DM, Porn-Ares MI, Coppola S, Burgess DH, Orrenius S. Protease involvement in fodrin cleavage and phosphatidylserine exposure in apoptosis. J Biol Chem 1996; 271 : 31075-31085.

41. Jahchan NS, Ouyang G, Luo K. Expression profiles of SnoN in normal and cancerous human tissues support its tumor suppressor role in human cancer. PLOS One 2013; 8: e55794. 
42. Roderick $\mathrm{HL}$, Cook SJ. $\mathrm{Ca}^{2+}$ signalling checkpoints in cancer: remodelling $\mathrm{Ca}^{2+}$ for cancer cell proliferation and survival. Nat Rev Cancer 2008; 8: 361-365.

43. Akl H, Bultynck $\mathrm{G}$. Altered $\mathrm{Ca}(2+)$ signaling in cancer cells: proto-oncogenes and tumor suppressors targeting $\mathrm{IP}_{3}$ receptors. Biochim Biophys Acta 2013; 1835: 180-193.

44. Fosgerau K, Hoffmann T. Peptide therapeutics: current status and future directions. Drug Discov Today 2015; 20: 122-128.

45. Miller MJ, Foy KC, Kaumaya PT. Cancer immunotherapy: present status, future perspective, and a new paradigm of peptide immunotherapeutics. Discov Med 2013; 15: 166-176.

46. Walensky LD, Kung AL, Escher I, Malia TJ, Barbuto S, Wright RD et al. Activation of apoptosis in vivo by a hydrocarbon-stapled BH3 helix. Science 2004; 305: 1466-1470.

47. LaBelle JL, Katz SG, Bird GH, Gavathiotis E, Stewart ML, Lawrence C et al. A stapled BIM peptide overcomes apoptotic resistance in hematologic cancers. J Clin Invest 2012; 122: 2018-2031.

48. Han B, Park D, Li R, Xie M, Owonikoko TK, Zhang G et al. Small-molecule Bcl2 BH4 antagonist for lung cancer therapy. Cancer Cell 2015; 27: 852-863.
49. Artymovich K, Appledorn DM. A multiplexed method for kinetic measurements of apoptosis and proliferation using live-content imaging. Methods Mol Biol 2015; 1219: 35-42.

(c) (i) Cell Death and Disease is an open-access journal published by Nature Publishing Group. This work is licensed under a Creative Commons Attribution 4.0 International License. The images or other third party material in this article are included in the article's Creative Commons license, unless indicated otherwise in the credit line; if the material is not included under the Creative Commons license, users will need to obtain permission from the license holder to reproduce the material. To view a copy of this license, visit http://creativecommons.org/licenses/by/4.0/

Supplementary Information accompanies this paper on Cell Death and Disease website (http://www.nature.com/cddis) 